\title{
Co-Surge in Bi-Turbo Engines: Measurements, Analysis and Control
}

\author{
Andreas Thomasson and Lars Eriksson
}

\section{Linköping University Post Print}

\section{Tweet}

N.B.: When citing this work, cite the original article.

Original Publication:

Andreas Thomasson and Lars Eriksson, Co-Surge in Bi-Turbo Engines: Measurements, Analysis and Control, 2014, Control Engineering Practice, (32), 113-122.

http://dx.doi.org/10.1016/j.conengprac.2014.08.001

Copyright: Elsevier

http://www.elsevier.com/

Postprint available at: Linköping University Electronic Press

http://urn.kb.se/resolve?urn=urn:nbn:se:liu:diva-105686 


\title{
Co-Surge in Bi-Turbo Engines - Measurements, Analysis and Control
}

\author{
Andreas Thomasson ${ }^{\mathrm{a}}$, Lars Eriksson ${ }^{\mathrm{a}}$ \\ ${ }^{a}$ Vehicular Systems, Dept. of Electrical Engineering, Linköping University, SE-581 83 Linköping, Sweden, \{andreast,larer\}@isy.liu.se
}

\begin{abstract}
In parallel turbocharged V-engines, with two separate air paths connected before the throttle, an oscillation in the flow can occur. If the compressor operates close to the surge line, typically during low speed and high load, and a disturbance alters the mass flow balance, the compressors can begin to alternately go into surge. This phenomenon is called co-surge and is unwanted due to high noise and risk for turbocharger destruction. Co-surge is measured on a test vehicle in a chassis dynamometer and the system analyzed and modeled using a mean value engine model. The investigation shows that the alternating compressor speeds have an important role in the prolonged oscillation. A reconstruction of the negative flow from measurements is made and compared to simulation results, showing similar amplitudes, and supports the model validation. A new co-surge detection algorithm is presented, suitable for a pair of sensors measuring either mass flow, boost pressure or turbo speed in the two air paths. Furthermore, a new controller is proposed that uses a model based feedforward for the throttle, together with wastegate actuation to force the compressor speeds together and improve balance at the recovery point. This has shown to be sufficient with moderate to high pressure ratios over the throttle, only for zero or very low pressure drop the use of bypass valves are necessary. The advantage of not opening the bypass valves is a smaller drop in boost pressure which also reduces the torque disturbance. The performance of the controller is evaluated both in simulation and in the test vehicle.
\end{abstract}

Keywords: Compressor surge, surge detection, surge control, engine modeling, engine control

\section{Introduction}

The automotive industry constantly strives to reduce fuel consumption and emissions of the internal combustion engine. One strategy that has proved to be successful over the years is to replace naturally aspirated engines with smaller turbocharged engines, Emmenthal et al. (1979); Watson and Janota (1982). Turbocharging increases air density in the intake which increase power density and thus allows the turbocharged engine to produce the same maximum power as a comparatively larger naturally aspirated engine. This is beneficial in low- to mid-load operating points where the engine usually operates, since pumping and friction losses are reduced, Guzzella et al. (2000). More advanced turbocharging concepts are being developed to further increase power density, Petitjean et al. (2004). A configuration that has increased in popularity is the use of two parallel identical turbochargers for V-type engines, one powered by each bank of cylinders. This allows the turbines to be mounted closer to the exhaust ports than if a single turbocharger where to be used, which reduces heat losses and makes better use of the pulsating flow from the exhaust, allowing more energy to be extracted trough the turbine.

In the most common parallel turbocharged configuration, the two air paths are connected before the throttle and a single throttle and intake manifold are used. This introduces an interesting balancing problem, since the same total mass flow can be realized with different flows from each air path. For balanced operation these should always be equal, but if the flow from one air path should drop for some reason, the other will start to take over, providing more flow. This interaction between the compressors is remarkable when operating close to the surge line, if the balance between the compressors are disturbed and one compressor enters surge. That mass flow will then drop to zero or below, while the other compressor will produce approximately twice the flow, depending on the shape of the compressor speed line as the pressure ratio drops. When the surging compressor recovers it will have a higher speed than the first compressor and risks pushing that compressor into surge instead, starting an oscillation between the air paths called cosurge. Failing to quell this oscillation will result in unwanted sound, drop in torque and in worst case, compressor damage.

This phenomena is not new, it was mentioned already in Watson and Janota (1982), but has received very little attention in the literature. Compressor surge is otherwise a well studied phenomena, and a well known and utilized result is the MooreGreitzer model, see Greitzer (1981). A rich treatment of surge modeling and control can also be found in for example Willems and de Jager (1998) or Gravdahl (1998). Most work has been done on turbo machinery with gas turbines. There are few studies focusing on automotive size turbochargers, where most utilizes the Moore-Greitzer, see e.g. Ammann et al. (2001) or Leufvén and Eriksson (2008). Resent studies on surge in automotive engines combine the Moore-Greitzer model with a 1D gas-dynamic model for the pipes around the compressor, see for example Galindo et al. (2008, 2011).

\subsection{Contributions and Outline}

One main contribution in this paper is an analysis of the cosurge oscillation, using both measurements from a test vehicle 
in chassis dynamometer and simulations. The analysis results in a new controller that tries to force the turbo speeds together during co-surge. The controller takes ideas from Thomasson and Eriksson (2013), but uses a model based feedforward for the throttle, and wastegate actuation to increase stability and enable faster recovery from co-surge. The controller is evaluated both in simulation and test vehicle. The simulations are based on a Mean Value Engine Model (MVEM) developed in Thomasson and Eriksson (2011), which is briefly summarized in the paper for completeness. Measurements of co-surge are also presented with an attempt to reconstruct the negative flow that can't be measured by the mass flow sensors, which is then compared to simulation results. In addition, a new cosurge detection algorithm is presented that uses a pair of sensors, measuring either mass flow, boost pressure or turbo speed in the two air paths.

Section 2 describes the test vehicle and the experimental setup used for the measurements and experiments in the paper. In Section 3 measurements of co-surge are presented, and the phenomena is described and compared to normal surge in a single compressor. Section 4 outlines a control oriented Mean Value Engine Model (MVEM) able to capture the quantitative behavior of co-surge. The model is used both in the analysis and as part of the controller validation in the following sections. This is followed by an analysis of the co-surge oscillation in Section 5. Detection and control of co-surge are the subject of Section 6 and 7 respectively, which includes validation both in simulation and test vehicle, followed by conclusions in Section 8 .

\section{Test setup}

The test vehicle is equipped with a spark ignited gasoline V6-engine with two parallel turbochargers, each powered from one bank of cylinders. A sketch of the engine is shown in Fig. 1, that also defines the nomenclature which is also available in Appendix A. The engine is equipped with three hot film mass flow sensors. The total flow is measured $10 \mathrm{~cm}$ after the air filter, $30 \mathrm{~cm}$ before the air path is divided. The two other, that measure the flow in each path, are placed $10 \mathrm{~cm}$ after the division of the air path, approximately $80 \mathrm{~cm}$ before the compressors. Hot film mass flow sensors are fast with time constants of around $10 \mathrm{~ms}$ Westbrook and Turner (1994). Pressures are measured before and after each compressor, before the throttle and in the intake manifold. Approximately $3 \mathrm{~m}$ of pipe connects the pressure sensors with the measurement point, which reduces the measured in-cycle variations and introduces a time delay of about $10 \mathrm{~ms}$. The exception is the $p_{\text {im }}$ sensor that is mounted directly at the intake manifold. The turbochargers are equipped with speed sensors.

The measurement and control system is a dSpace MicroAutoBox and a RapidPro system, connected to a computer running ControlDesk. Most measurements are sampled in $100 \mathrm{~Hz}$, however the total mass flow and intake manifold pressure are received from the CAN bus and only updates in $12.5 \mathrm{~Hz}$. The actuators used by the control algorithm are the throttle, the bypass valves and the wastegates. The throttle and wastegate are

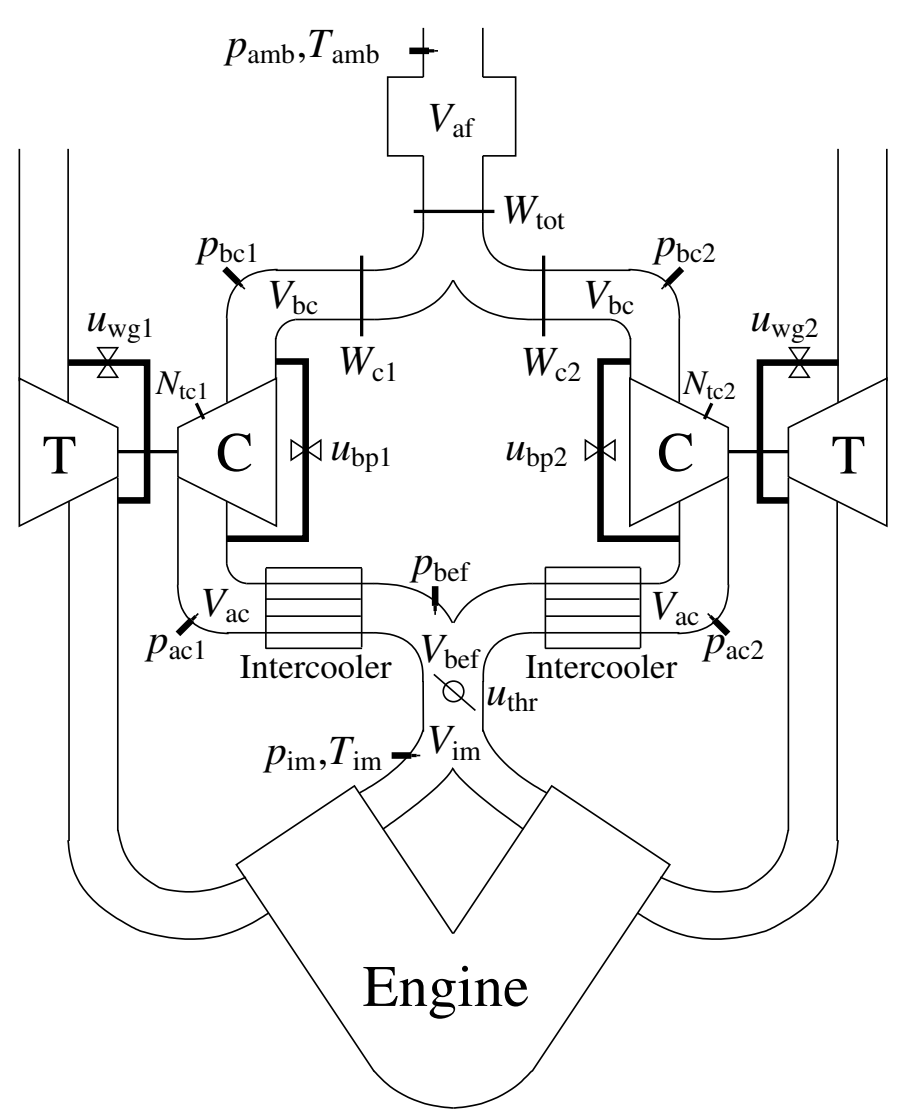

Figure 1: A sketch of the bi-turbocharged engine configuration. A mass flow sensor, $W_{\text {tot }}$, is positioned after the air filter and two more, $W_{\mathrm{c} 1}$ and $W_{\mathrm{c} 2}$, directly after the air path split up. The actuators used in the control section are the throttle, $u_{\mathrm{thr}}$, the bypass valves, $u_{\mathrm{bp} 1}, u_{\mathrm{bp} 2}$, and the wastegates, $u_{\mathrm{wg} 1}, u_{\mathrm{wg} 2}$. Pressures are measured before and after each compressor, before the throttle and in the intake manifold.

continuously actuated while the bypass valves are of ON/OFF type. For the tests the vehicle is mounted in a vehicle dynamometer with one electric motor connected to each wheel on the rear axle. Although the test vehicle is equipped with the mass flow, pressure, temperature and turbo speed sensors in Fig. 1 for modeling purposes, the detection algorithm only uses either pair of $p_{\text {ac }}$, MAF or $N_{\text {tc }}$ sensors. The proposed controller uses $p_{\text {ic }}$ and $p_{\text {im }}$, and in the controller with balancing also the two turbo speed sensors are utilized.

\section{Surge and co-surge}

Compressor surge is well known system instability phenomena. When the compressor mass flow gets too low, at high pressure ratio, the mass flow can stall, start to fluctuate and even reverse through the compressor. Surge can be categorized in at least four different types, Mild surge, Classical surge, Modified surge and Deep surge, de Jager (1995). Among these four only deep surge has reversed flow, and is thus the one most closely related to co-surge which has reversed flow during large part of the surge cycle, as will be shown shortly.

The left plot of Fig. 2 shows an example of surge measured in the test vehicle. A small throttle closing is made at $t=0 \mathrm{~s}$ 

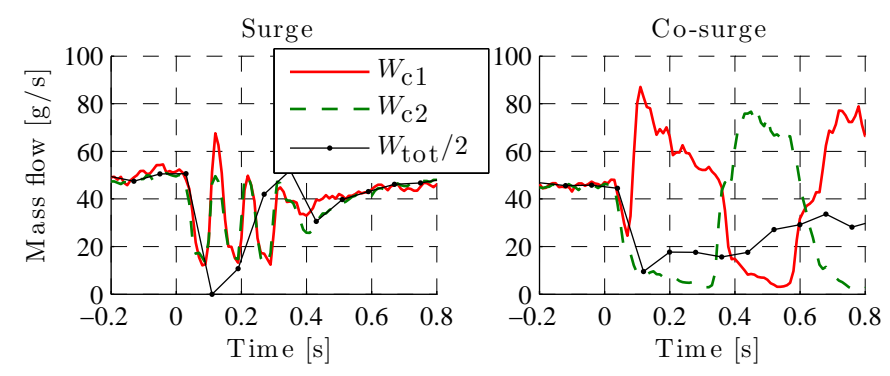

Figure 2: A comparison between surge (left plot) and co-surge (right plot), measured on the test vehicle. In the first case both compressors go into surge simultaneously, similar to surge in a single compressor system. In the second case, the first compressor takes over all mass flow when the second compressor surges. Upon recovery the first compressor is pushed into surge, starting an oscillation with alternating flow reversals. Note that the mass flow sensors can't measure negative flow.

which pushes both compressors into surge. The mass flow oscillation is around $10 \mathrm{~Hz}$ and dies out after a few cycles. An example of co-surge is shown in the right plot. The situation is similar, a throttle disturbance is made at $t=0 \mathrm{~s}$, but instead of going into surge simultaneously, when one compressor goes into surge the other produces more mass flow instead. When the surging compressor recovers it pushes the other into surge and vise versa, resulting in an oscillation which doesn't die out unless some measure is taken. Compared to normal surge, the frequency of co-surge is much lower and the magnitude of the mass flow and turbo speed oscillation are larger. A significant reason for this is that the pressure after the surging compressor drops much slower compared to normal surge as a result of the mass flow form the other compressor into that volume. Therefore the time it takes for the pressure ratio over the compressor to reach the pressure ratio for zero mass flow, and thus recover, becomes much longer.

The mass flow sensors can't measure negative flow, but by comparing the total mass flow to the sum of the two separate flows, it is clear that the sum of the two flows is larger than the total flow. An estimation of the flow reversal can be computed by assuming that the total flow is not reversed, and that the total flow and the larger measured flow is correct, giving:

$$
\begin{aligned}
& \widehat{W}_{\mathrm{c} 1}= \begin{cases}W_{\mathrm{tot}}-W_{\mathrm{c} 2} & \text { if } W_{\mathrm{c} 1}<W_{\mathrm{c} 2} \& W_{\mathrm{tot}}-W_{\mathrm{c} 2}<0 \\
W_{\mathrm{c} 1} & \text { otherwise }\end{cases} \\
& \widehat{W}_{\mathrm{c} 2}= \begin{cases}W_{\mathrm{tot}}-W_{\mathrm{c} 1} & \text { if } W_{\mathrm{c} 2}<W_{\mathrm{c} 1} \& W_{\mathrm{tot}}-W_{\mathrm{c} 1}<0 \\
W_{\mathrm{c} 2} & \text { otherwise }\end{cases}
\end{aligned}
$$

The resulting plot for the same measurement as the right plot of Fig. 2 (and Fig. 4) is shown in Fig. 3. This estimation of the reversed flow is of course very rough but the magnitude is large enough to conclude that reversed flow does occur during a large part of the surge cycle. Note this calculation does not take into account mass accumulation in the pipes due to the pressure fluctuation, but this effect is very small and would only introduce an error of approximately $1 \%$ in the flow estimation. This is negligible compared to the error introduced by the low sampling rate of the total flow signal. If more accuracy is desired in

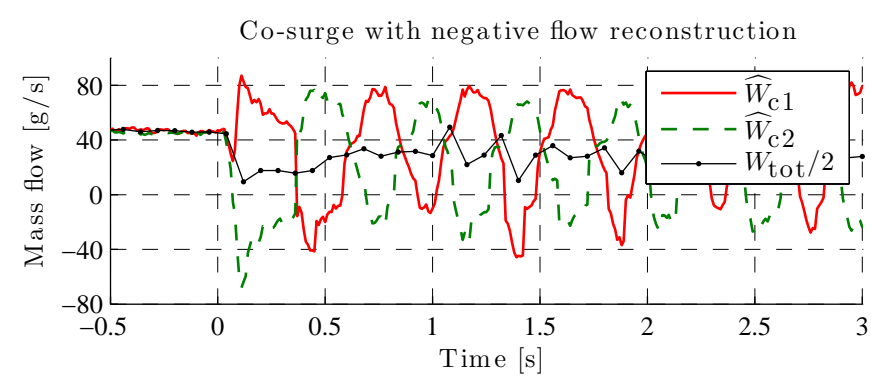

Figure 3: An estimation of the reversed mass flow based on the total mass flow sensor. The estimates show that reversed flow with significant magnitude occurs during a large part of the surge cycle.

the estimation, an observer could be constructed that uses total flow sensor and the largest of the two separate flows to estimate the other, but then the total flow needs to be sampled faster, which was not possible in the test vehicle installation. Another option would be to mount another pair of mass flow sensors in the opposite direction.

Fig. 4 gives a more detailed picture of the phenomenon. At $t=0 \mathrm{~s}$ the throttle closes by $10 \%$ for $0.3 \mathrm{~s}$ and is then returned to its original position. At first both mass flows drop but shortly afterward one compressor rapidly recovers to produce all mass flow while the other goes into surge. When the second compressor recovers it has a higher turbo speed than the first compressor, and as a result will produce more mass flow. The reason for this is that the compressor that surges doesn't consume any torque, while the compressor which produces higher mass flow consumes more torque. If the operating point is too close to the surge line, the first compressor is then pushed into surge which results in a sustained oscillation with alternating flow reversals in each air path. Note both turbo speeds drop during the disturbance, even for the surging compressor. This is probably due to lower energy to the turbine because of the lower mass flow. Additionally the boost pressure peak causes the boost controller to open the wastegates at the beginning of the transient, releasing some of the pressure before the turbines.

Despite that the non surging compressor is producing more flow, it does not fully counteract the loss of the other compressor mass flow, and the total mass flow drops during the oscillation, resulting in a drop in torque. The turbo speed will also oscillate with a phase lag of $90^{\circ}$ compared to the mass flow.

\section{Control oriented engine model}

To be able to perform fast simulations of a complete engine model on a standard desktop computer, zero dimensional mean value engine models are very attractive. A mean value model of an SI engine is presented in for example Hendricks and Sorenson (1990). A component based turbo charged MVEM was outlined in Eriksson et al. (2002); Eriksson (2007), which is the base for the model used in this paper. The model was first presented in Thomasson and Eriksson (2011) but is briefly summarized here for completeness and readability of the paper. The methodology is to divide the model into components, flow re- 

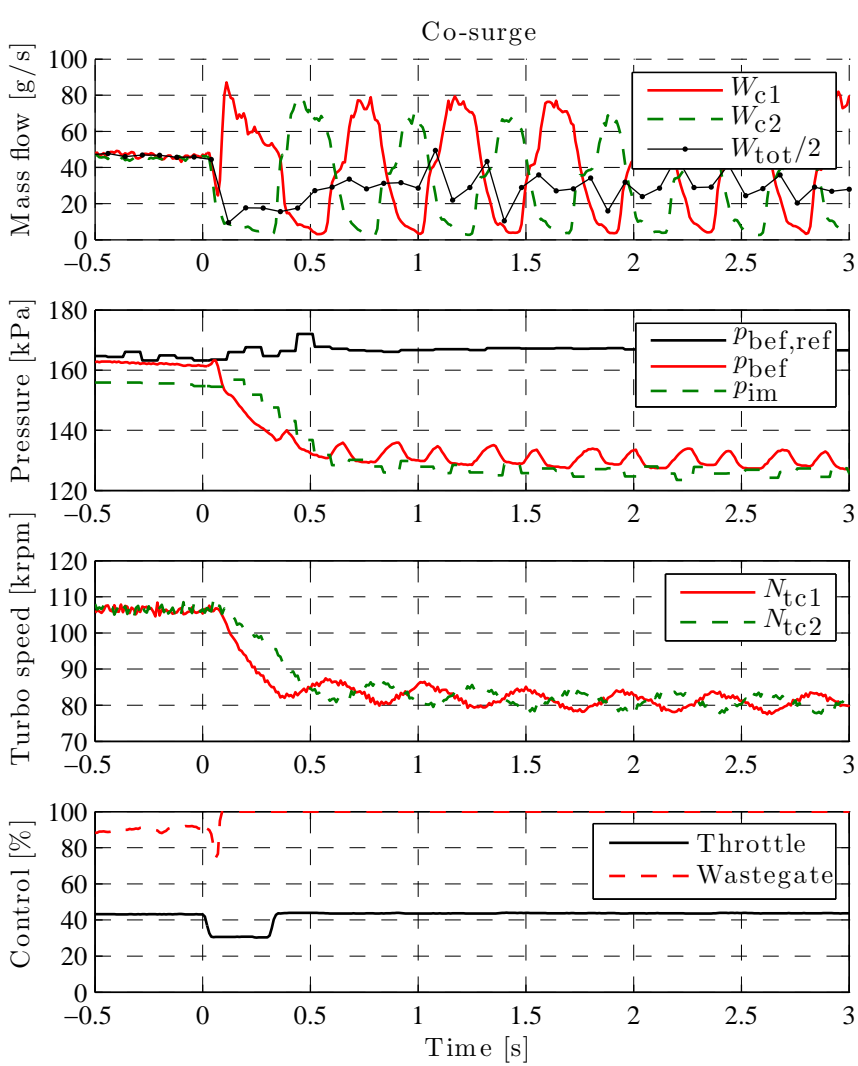

Figure 4: Co-surge measured on the test vehicle. A throttle disturbance is made at $t=0 \mathrm{~s}$ and initially both mass flows drop. Shortly afterward the mass flow through the first compressor rapidly increase to produce all mass flow as the other goes onto flow reversal.

strictions and control volumes. The restriction components determine the mass flow through them depending on surrounding conditions, and the control volumes contain states for pressure and temperature. The components are then arranged in series, where a control volume always follow a restriction and vise versa.

For this application these components can be arranged in a structure representing the parallel turbocharged engine in Fig. 1. An overview of the simulink model is shown in Fig. 5. The blue blocks are control volumes, the magenta colored blocks are restrictions and the two yellow blocks are a collection of other blocks, that contain all doubled components in the air path such as compressor, turbine, intercooler, on side of the V-engine etc.

\subsection{Compressor model}

From the measurements in section 3 it is clear that in order to capture the co-surge phenomena, the engine model needs to handle reverse flow through the compressors. One way to achieve this is to use the well known and well tested MooreGreitzer model, Greitzer (1976, 1981). The model was first developed for axial flow compressors, but has been shown to work also for centrifugal compressors in Hansen et al. (1981). The model includes an additional state for the mass flow which

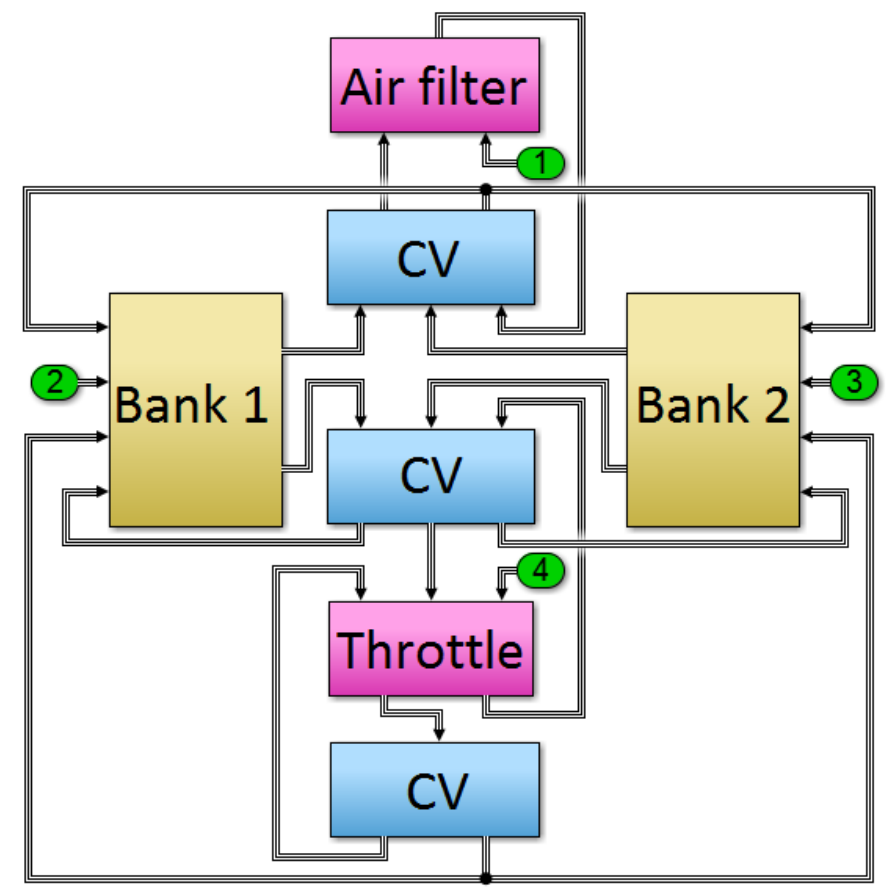

Figure 5: Overview of the simulink model for the parallel turbocharged engine. Magenta colored blocks are restrictions (Air filter, Throttle), blue are control volumes $(\mathrm{CV})$ and yellow blocks are collections of other blocks (Bank 1,2), in this case all doubled blocks: compressor, compressor $\mathrm{CV}$, intercooler, cylinder bank, exhaust manifold $\mathrm{CV}$, turbine, turbine $\mathrm{CV}$ and exhaust restriction.

is calculated from the state equation:

$$
\frac{d W_{\mathrm{c}}}{d t}=\frac{\pi D^{2}}{4 L}\left(\hat{p}_{\mathrm{ac}}-p_{\mathrm{ac}}\right)
$$

The idéa behind the model is that the difference between the pressure built by the compressor, $\hat{p}_{\text {ac }}$, and the actual pressure after the compressor, $p_{\text {ac }}$, results in a force on a flow plug after the compressor, with length $L$ and the diameter of the pipe $D$, see the top of Fig. 6 .

The model requires a description of the pressure build up as a function of compressor speed and mass flow, which is given by the compressor map. To reduce the model size a simple parameterization of the map is used in this investigation. The parameterization is based on the dimensionless numbers for flow, $\Phi$, and energy, $\Psi$, defined as in Dixon (1998)

$$
\Phi=\frac{W_{\mathrm{c}}}{N D^{3}} \frac{R T_{\mathrm{bc}}}{p_{\mathrm{bc}}}
$$

$$
\Psi=\frac{c_{\mathrm{p}} T_{\mathrm{bc}}\left(\Pi_{\mathrm{c}}^{(\gamma-1) / \gamma}-1\right)}{N^{2} D^{2}}
$$

and depends on the compressor diameter, $D$, the temperature before the compressor, $T_{\mathrm{bc}}$, the specific gas constant, $R$, and $\Pi_{\mathrm{c}}=\hat{p}_{\mathrm{ac}} / p_{\mathrm{bc}}$. In the $\Phi-\Psi$ domain, the compressor speed lines are gathered into almost a single line (Eriksson, 2007), and the relation between $\Phi$ and $\Psi$ can be used to model the pressure build up in the compressor as a function of mass flow and compressor speed. 

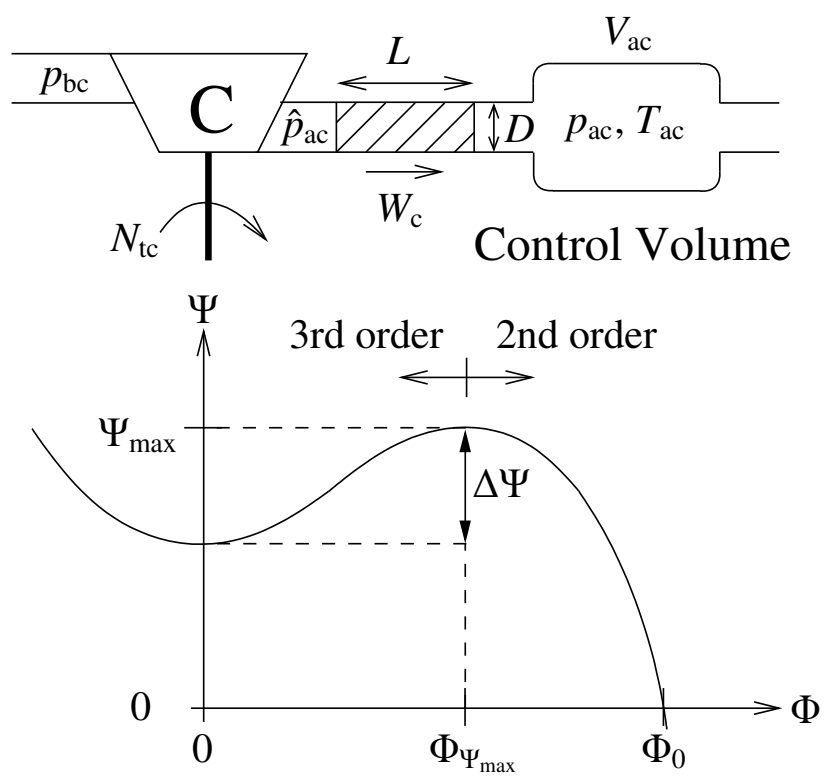

Figure 6: Top: The Moore-Greitzer compressor model. The pressure difference $\hat{p}_{\text {ac }}-p_{\text {ac }}$ results in an acceleration of the flow plug, with length $L$ and pipe diameter $D$, that governs the mass flow.

Bottom: Parameterization of the $\Phi-\Psi$ function.

\subsection{Turbo shaft torque balance}

The torque balance of the compressors are modeled with Newtons second law of motion for rotating systems, using the power balance between the turbine and the compressor with a viscous friction loss:

$$
J_{\mathrm{tc}} \frac{\omega_{\mathrm{tc}}}{d t}=\frac{P_{\mathrm{t}}}{\omega_{\mathrm{tc}}}-\frac{P_{\mathrm{c}}}{\omega_{\mathrm{tc}}}-k_{\mathrm{fric}} \omega_{\mathrm{tc}}
$$

The parameters are the compressor inertia, $J_{\text {tc }}$, the turbine power $P_{\mathrm{t}}$, the compressor power $P_{\mathrm{c}}$, the turbo speed, $\omega_{\mathrm{tc}}$, and the friction coefficient $k_{\text {fric }}$.

\subsection{Model validation}

The models ability to capture the measured co-surge phenomena is evaluated by comparing simulations with the measured co-surge cycles. Fig. 7 show a simulation under the same operating conditions as the measurement in Fig. 4, at time $t=0 \mathrm{~s}$ a throttle disturbance is made and the system enters cosurge. The model is clearly able to capture the main behavior in the measurements such as the frequency and amplitude of the mass flow, pressure and turbo speed oscillations. The turbo speed oscillation lags the mass flow by $90^{\circ}$ which is in agreement with the measurement. The main difference is the initial drop in turbo speed that is not captured by the model. There is also a more rapid transition between negative and positive flow in simulations, this is partly due to sensor dynamics and partly due to inertia of the gas in the pipes which are not included in the model. This was investigated in Thomasson and Eriksson (2011) but did not have an significant impact on the overall behavior and is therefore excluded form the model. The mean value engine model used also does not include pulsations from the opening and closing of the intake valves, this effects
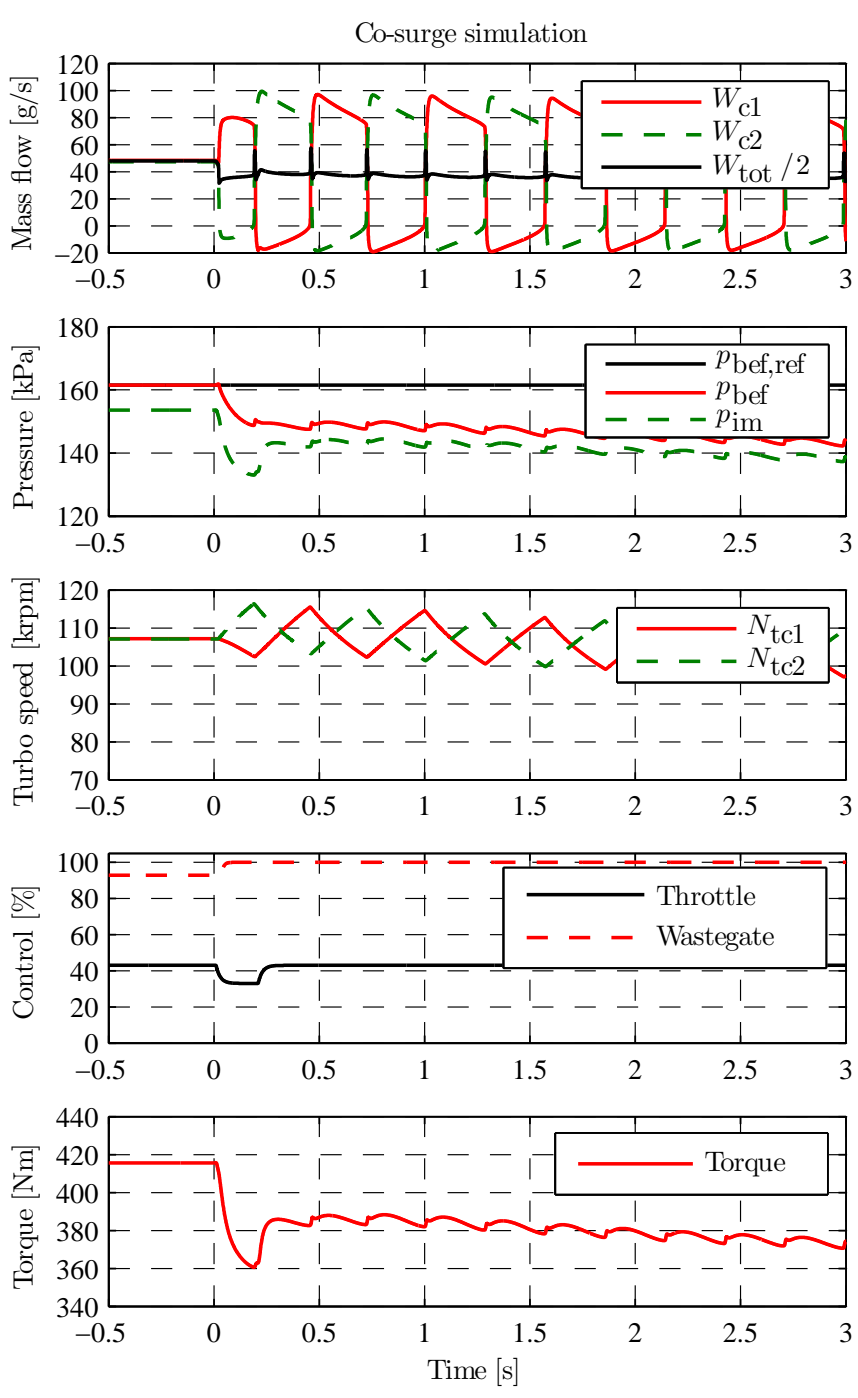

Figure 7: Co-surge resulting from simulations under similar operating conditions as the measurements in Fig. 4. The main behavior is captured by the model, both frequency and amplitude of the mass flow, pressure and turbo speed oscillations.

the surge margin see for example Galindo et al. (2009). For accurately predicting the exact operating point where surge begins, this should be taken into account, but that has not been the focus of this study.

Due to the decrease in total mass during co-surge the torque drops around $35 \mathrm{Nm}$ during the oscillation. The larger initial $50 \mathrm{Nm}$ drop is due to the throttle closing used as disturbance, and should not be regarded as a result of the co-surge oscillation.

The simulation should also be compared to the estimation of the reversed flow in Section 3, Fig. 3. The magnitude is similar except for the spikes down to $-40 \mathrm{~g} / \mathrm{s}$, which is not seen in simulation. The duration of the spikes might however be overestimated due to low sampling rate of the $W_{\text {tot }}$ signal, which is received from the CAN bus at $12.5 \mathrm{~Hz}$. 


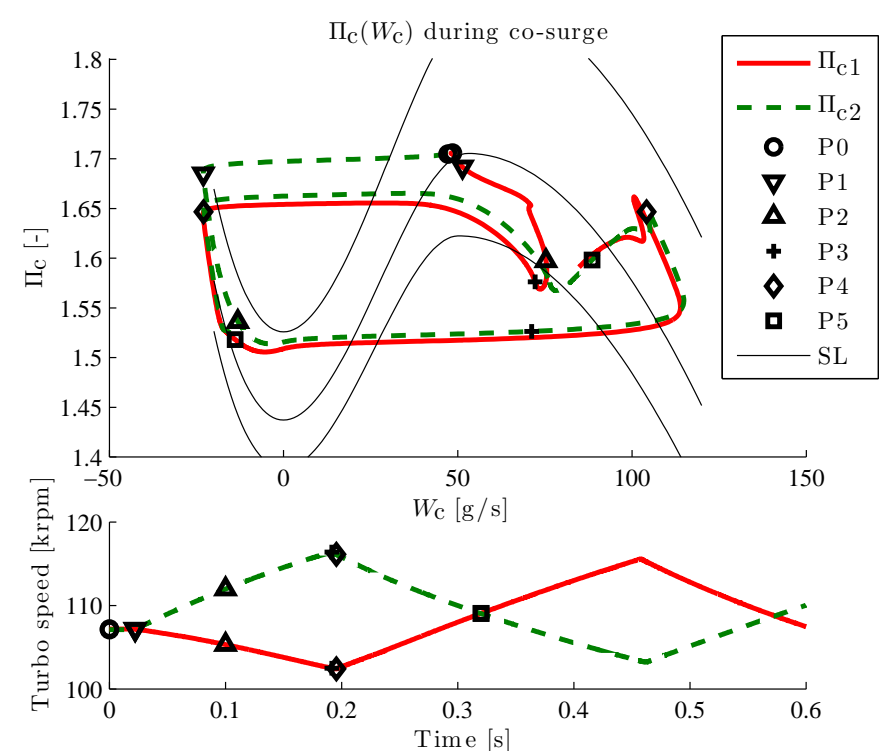

Figure 8: Top: Pressure ratio versus mass flow for the compressors during the the beginning of co-surge (the first $0.6 \mathrm{~s}$ of the simulation in Fig. 7). In the background are the compressor speed lines (SL) for the initial turbo speed as well as the maximum and minimum speed during the cycle plotted.

Bottom: The corresponding compressor speeds. Note that point P3 and P4 are very close in time and therefore almost on top of each other in this subfigure.

\section{Co-surge analysis}

When the system enters co-surge the speed of the two turbochargers start to diverge. When the surging compressor recovers it will therefore be at a higher speed than the other compressor, producing more flow at a lower pressure ratio. The compressor with the lower flow will therefore be pushed up to the left in the compressor map after the recovery, possibly past the surge line. The top subfigure of Fig. 8 shows the pressure ratio over the compressors plotted against the compressor mass flows during the onset of co-surge, below the compressor speeds versus time is shown (this is the first $0.6 \mathrm{~s}$ of the simulation in Fig. 7). At the starting point (P0) the flows are slightly unbalanced when a disturbance in throttle is made. The mass flows rapidly diverge, at the point (P1), $0.2 \mathrm{~s}$ after the disturbance, the mass flow has reversed, and the pressure ratio starts to drop. The point (P2) is in the middle of the first surge cycle, the pressure now drops slower as compressor one produces more flow due to the lower pressure ratio. When the surging compressor recovers and the mass flows have become equal (P3), the turbo speed of that compressor is higher. The pressure ratio is also lower since during surge the direction of the mass flow is from the side with positive flow to the surging side. This higher speed and lower pressure ratio will make the mass flow rapidly increase, pushing the other compressor up to the left in the map. At the point when equal pressure is reached (P4) the other compressor has already entered surge, and the mass flow reversed. The surging compressor will now start to accelerate and the other decelerate, the turbo speeds will be equal approximately during the middle of the next surge cycle (P5) and then diverge again, and the oscillation continues.
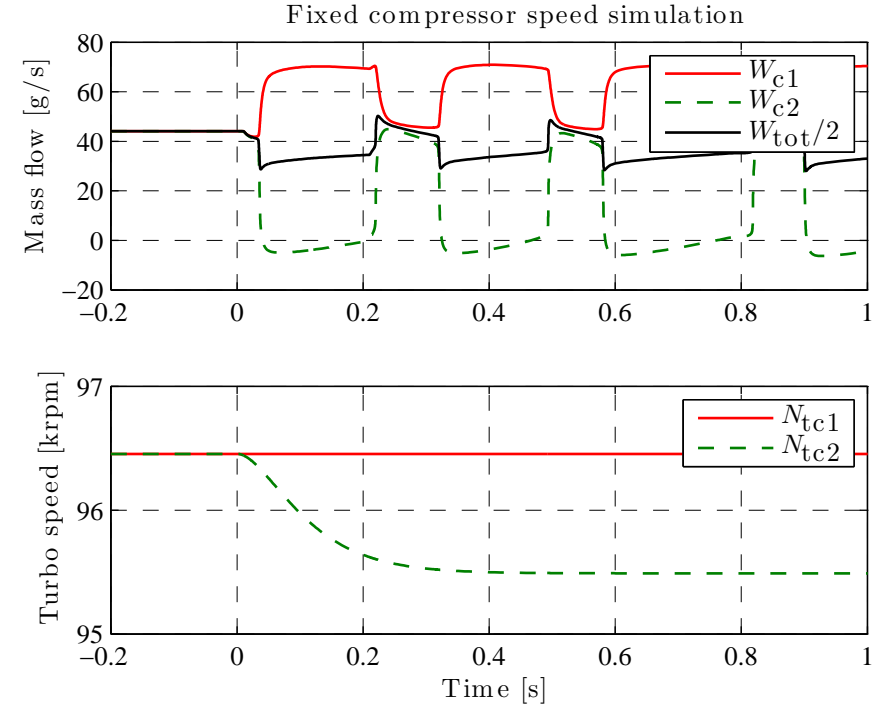

Figure 9: Simulation with controlled compressor speeds close to the surge line. At $\mathrm{t}=0$ the speed for compressor two is lowered by $1 \%$ and that compressor enters surge. Instead of alternating flow reversals only the compressor with lower speed continues to surge.

The key here is the different compressor speeds when the compressor flow recovers, which causes the mass flow to increase very rapidly upon recovery, pushing away the other compressor. That this is the main cause of the continuing oscillation co-surge can be strengthened by simulations with controlled compressor speeds. In Fig. 9 such a simulation is shown. At first the compressor speeds are equal, but at $t=0$ a change in the speed for compressor two is made. Instead of an alternating flow reversals the compressor with the lowest speed will now be the only compressor that surges. With controlled compressor speeds it could also be the case that the compressor with lower speed goes into reverse flow and never recovers. This depends on if the other compressor is able to produce all the mass flow without the pressure dropping below the pressure ratio at zero flow for the surging compressor, which depends on the shape of the speed lines in the compressor map.

\subsection{Implications for control}

The conclusion is that the compressor speeds needs to be balanced to recover from co-surge with as much margin as possible. For identical compressors and air paths, this would mean controlling the speed difference of the compressors to zero. In case of discrepancies between the compressors, a reference for the desired turbo speed difference could be set, the controller would then balance toward the this difference instead of zero.

When the system has not entered co-surge, balanced compressor speeds are achieved by balancing the mass flows. When the system enters co-surge however, the compressor with highest flow will not have the highest compressor speed. A controller that tries to balance the mass flows by increasing the compressor speed for the compressor with lower flow, by closing the corresponding wastegate, would therefore worsen the situation. If the system relies on parallel mass flow sensors 


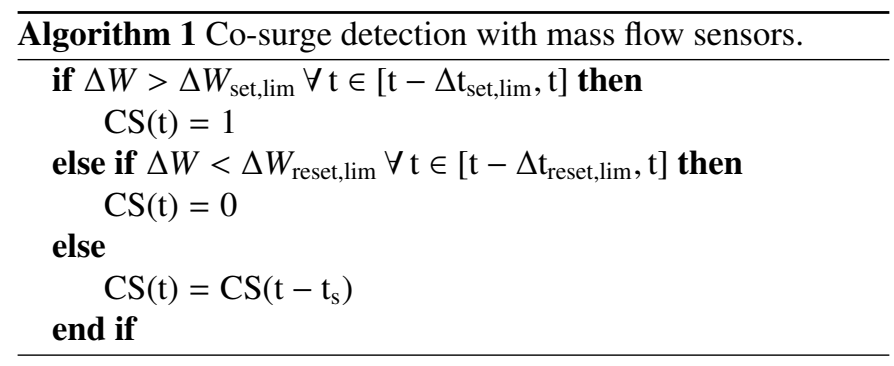

to balance the compressor operation, the system consequently needs to detect if co-surge occurs and turn off the balancing.

Additionally the total mass flow drops when the system enters co-surge. To reduce torque disturbance the controller should therefore try to increase the mass flow when entering co-surge. This will also increase the margin to the surge line at the recovery point. The next section treats detection of co-surge followed by co-surge control in Section 7.

\section{Detection}

The possibility to detect co-surge, as well as the accuracy and speed of the detection will depend on which sensors are available. This section investigates the performance of the detection with different available sensors. In this sections investigates detection using a pair of sensors, one in each air path, measuring either mass flow, pressure or turbo speed.

\subsection{Mass flow sensors}

When the system enters co-surge the mass flows will rapidly diverge. If the mass flow in each air-path is measured, the most straightforward is to use the difference in mass flow. In Thomasson and Eriksson (2011, 2013), a low-pass filtered difference and hysteresis was used for detection. In this paper another method is suggested, suitable for different sensor types.

By studying measurements it is clear that the difference in mass flow will be low for all operating points except when entering co-surge and for very short disturbances. Thus if the mass flow difference exceed a threshold for only a few samples it can be concluded that the system has entered co-surge. In the opposite direction, since the transition between positive and negative flow during co-surge is relatively fast, if the difference is below a threshold for a period of time that is longer than the transition time, the system is no longer in co-surge. This can be written as in Algorithm 1, where $C S$ is a boolean variable that indicate co-surge. The other variables are time, $\mathrm{t}$, the mass flow difference, $\Delta W$, the set and reset mass flow thresholds, $\Delta W_{\text {set,lim }}$

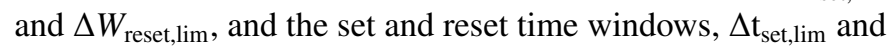
$\Delta \mathrm{t}_{\text {reset,lim }}$

An evaluation of the detection algorithm is shown in Fig. 10. The middle subfigure compares mass flow, pressures and turbo speed difference, and has been manually normalized to be comparable in the same figure. The thick solid line in the bottom subfigure shows that detection is made about $0.1 \mathrm{~s}$ after the disturbance when using mass flow sensors.
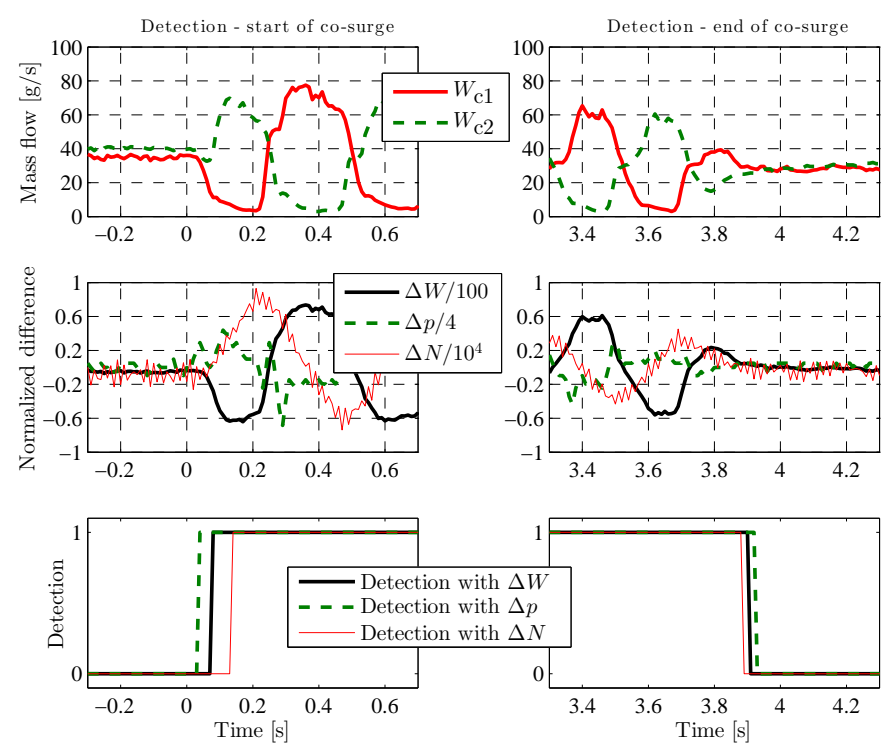

Figure 10: Evaluation of detection for beginning and end of co-surge using different sensors. Top: Mass flows in the two air paths. Middle: Mass flow, pressure and turbo speed difference, normalized to be comparable in the same figure. Bottom: Detection using mass flows (thick solid blue line), pressures (dashed green line) and turbo speeds (thin solid red line).

\subsection{Pressure sensors}

A cheaper option than mass flow sensors would be to use pressure sensors after each air path. When the mass flow in the first compressor reverses, there will be a flow from the high pressure side of the other compressor, trough the junction of the two air paths and back to the surging compressor. This is caused by a pressure difference which can be used for detected in a similar manner as the mass flow difference in Algorithm 1, by changing $\Delta W$ to $\Delta p$. Looking at $\Delta p$ in the middle subfigure of Fig. 10 it can be seen that it reacts faster then the other sensors, but is only large during the transients between positive and negative flow. This means that it is required that the pressure difference is small during longer period of time before it can be concluded that co-surge has ended, which means that

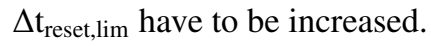

The dashed line in the bottom subfigure of Fig. 10 shows that detection with pressure difference is indeed faster than using mass flow sensors, detection is made already $0.04 \mathrm{~s}$ after the disturbance. Another reason that these sensors react faster is that they are located closer to the turbochargers compared to the mass flow sensors, which are placed directly after the air paths split, see figure 1. A downside with using pressure instead of mass flow sensors is that for unbalanced but positive flow the pressure difference is very small, making it unsuitable for balancing. it can also be harder to distinguish between surge and co-surge with pressure sensors since the pressure the difference is a lot smaller and looks similar normal surge, which is not the case for mass flow or speed sensors.

\subsection{Turbo speed sensors}

It was concluded in section 5 that it is important to keep the turbo speeds balanced, and the inclusion of turbo speed sensors 
could therefore be beneficial for balancing and control of cosurge. As pointed out earlier, when the system enters co-surge the turbo speeds will start do differ, and if turbo speed sensors are available these could be used for co-surge detection as well as control. The detection is not expected to be as fast using pressure sensors, because the speeds does not start to differ until the system has entered co-surge, which can be seen in the middle subfigure of Fig. 10. On the other hand, compared to using pressure sensors it very easy to distinguish between surge and cosurge, since the turbo speeds diverge a lot more during co-surge compared simultaneous surge in both compressors. The detection algorithm itself can be done very similar to Algorithm 1, but using turbo speed difference, $\Delta N$, instead of $\Delta W$, and different $\Delta \mathrm{t}$ limits. Turbo speed sensors could also be used as an alternative to parallel mass flow sensors for balancing during normal operation.

\subsection{Sensor combinations}

Pressure sensors are the fastest to detect when co-surge is about to begin, however they are also slowest to determine when co-surge has ended, which is fastest with turbo speed sensors. Combining these two would give the fastest detection of both the beginning and end of co-surge. However the difference in detection time is small, and if the control system requires mass flow measurement, adding a second sensor and putting them in the separate air paths might be the best option, since it allows direct measurement of the two separate flows. For the controller evaluation in the next section twin mass flow sensors are used.

\section{Co-surge control}

In the literature several methods for surge control in single compressors have been proposed, de Jager (1995). The most basic is surge avoidance, where the compressor is controlled with a safety margin to the surge line, Gravdahl (1998). Active surge control works by stabilizing the compressor in the otherwise unstable operating region to the left of the surge line, using a suitable actuator, for example a close-coupled valve after the compressor, air injectors, bleed valves, loudspeakers, see e.g. Willems and de Jager (1998); Gravdahl and Egeland (1999). Surge detection and avoidance strategies tries to avoid the drawbacks of operating with a safety margin by detecting the onset of surge and then act to move the operating point away from the unstable region, de Jager (1995).

Controlling co-surge is partly a different problem. When cosurge occurs due to a disturbance between the two mass flows, at a constant operating point, the corresponding point with balanced mass flows is stable. The objective of the control system is then to return this point with balanced flow and as little torque disturbance as possible. Failing to do that will result in unwanted sound, drop in toque and in worst case, compressor damage.

The actuators available for the controller are the throttle, the two bypass valves, and the two wastegates. Of these only the throttle and bypass yield a very rapid change in the compressor operating point, therefore at least one of these is needed for fast controller response if the system would enter co-surge. By opening the throttle, boost pressure is reduced for a given mass flow and the operating point moves to the right in the compressor map, away from the surge region. The mass flow will also increase, partly counteracting the reduction in total mass flow that occurs during co-surge. By opening the bypass valves, the pressure ratio is reduced and the mass flow felt by the compressor is increased by recirculating part of the compressed air. This also moves the operating point of the compressor away from the surge region, but boost pressure and actual mass flow is reduced, leading to greater torque disturbance.

The throttle opening is calculated by a model based feedforward that utilizes a compressible restriction model for the throttle mass flow:

$$
W_{\mathrm{thr}}=\frac{p_{\mathrm{bef}}}{\sqrt{T_{\mathrm{ic}} R}} A_{\mathrm{eff}}\left(u_{\mathrm{thr}}\right) \Psi\left(\frac{p_{\mathrm{im}}}{p_{\text {bef }}}\right)
$$

The throttle reference position is calculated by exchanging $p_{\text {im }}$ and $W_{\text {thr }}$ for the reference values $p_{\text {im,ref }}$ and $W_{\text {thr,ref. }}$ Solving for $u_{\text {thr }}$ gives:

$$
u_{\mathrm{thr}, \mathrm{ff}}=A_{\mathrm{eff}}^{-1}\left(\frac{W_{\text {thr,ref }} \sqrt{T_{\mathrm{ic}} R}}{p_{\text {bef }} \Psi\left(\frac{p_{\text {im,ref }}}{p_{\text {bef }}}\right)}\right)
$$

The mass flow reference, $W_{\text {thr,ref, }}$, is calculated using the volumetric efficiency of the engine

$$
W_{\text {thr,ref }}=\eta_{\text {vol }} \frac{2 p_{\text {im,ref }} N V_{\mathrm{D}}}{R_{\text {air }} T_{\text {im }}}
$$

Boost pressure drops when co-surge begins and the reference remains constant, the feedforward will immediately open the throttle as long as it would not make the intake pressure above the reference with the current boost pressure. Note that this requires a small pressure drop over the throttle to begin with so that the throttle is not already fully open. To avoid that the throttle closing after recovery pushes the system into surge again, the throttle closing after co-surge is rate limited

$$
u_{\mathrm{thr}, \mathrm{ff}}^{*}=\max \left(u_{\mathrm{thr}, \mathrm{ff}}, u_{\mathrm{thr}, \mathrm{ff}}\left(\mathrm{t}-\mathrm{t}_{\mathrm{s}}\right)-k / \mathrm{t}_{\mathrm{s}}\right)
$$

where $\mathrm{t}_{\mathrm{s}}$ is the sample time and $k$ is the maximum retard rate. In addition to this, if the pressure drop over the throttle is very low when co-surge begins, only opening the throttle is not enough to quell the oscillation, see Thomasson and Eriksson (2013). In that case actuating the bypass valves are necessary. The bypass control is implemented as

$$
u_{\mathrm{bp}}= \begin{cases}1, & \text { if } \mathrm{CS}=1 \text { and } \Delta p_{\mathrm{thr}}\left(\mathrm{t}_{\mathrm{CS}}\right)<\Delta p_{\mathrm{lim}} \\ 1, & \text { if } \mathrm{CS}=1 \text { and } p_{\mathrm{im}} \geq p_{\mathrm{im}, \mathrm{ref}} \\ 0, & \text { otherwise }\end{cases}
$$

where $\Delta p_{\mathrm{thr}}\left(\mathrm{t}_{\mathrm{CS}}\right)$ is pressure drop over the throttle when cosurge is detected and $\Delta p_{\text {lim }}$ is a threshold for opening the bypass valves.

\subsection{Controller evaluation}

The co-surge control strategy described by (6)-(9) has been evaluated both in simulation and test vehicle. For this evaluation twin mass flow sensors are used for detection. An example 

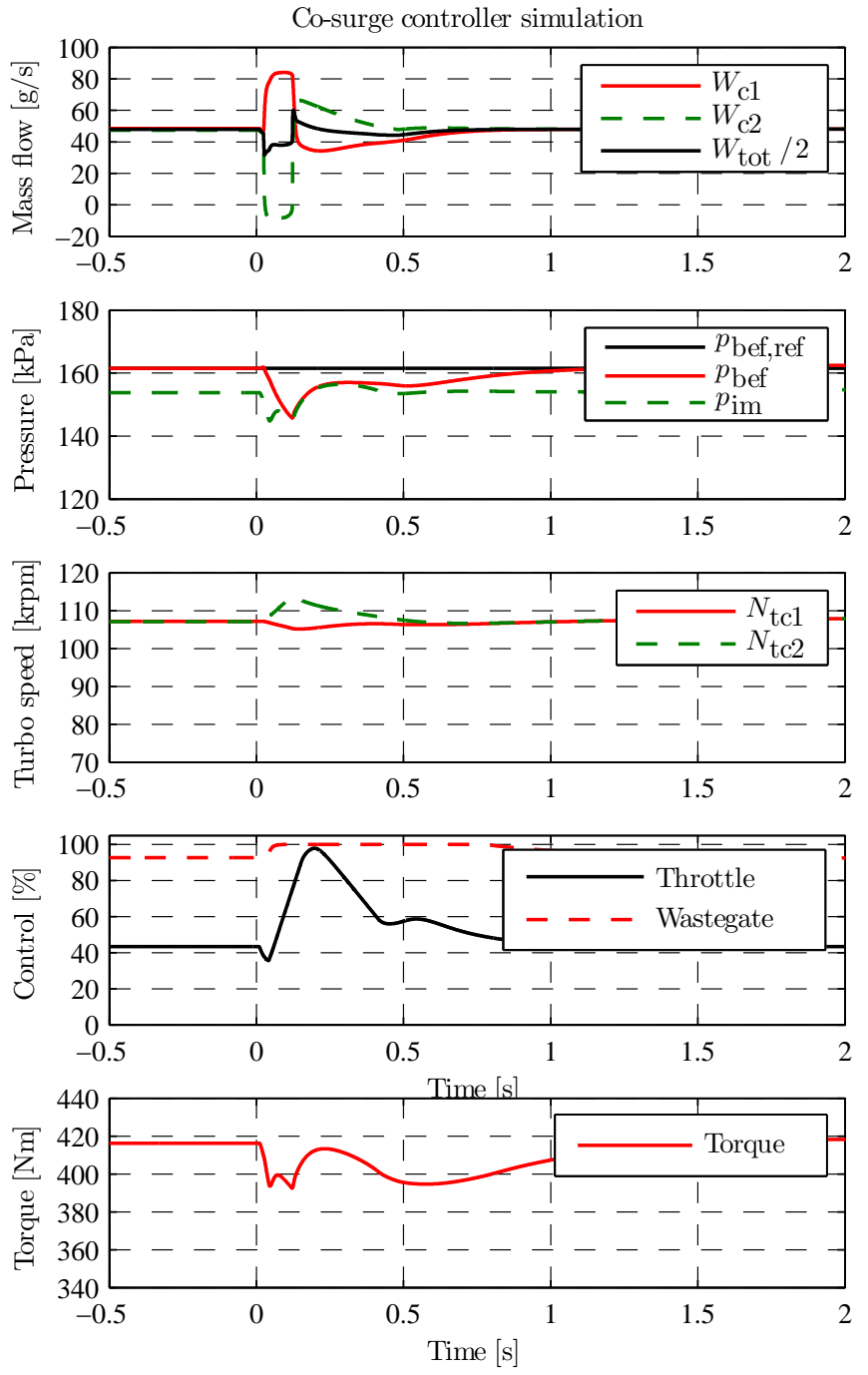

Figure 11: Simulation with the co-surge controller. At $\mathrm{t}=0 \mathrm{~s}$ a disturbance in throttle is made and the mass flows start to diverge. The detection and control algorithm detects the problem and opens the throttle. After less than $0.5 \mathrm{~s}$ the oscillation has been quelled and the mass flow difference limited, and after about $1 \mathrm{~s}$ the same stationary point as before the disturbance is reached.

from the simulations are shown in Fig. 11. The engine runs at a constant operating point close to the surge line. A small throttle disturbance is introduced at $\mathrm{t}=0$ and the mass flows rapidly diverge. The system detects co-surge and as a result of the dropping boost pressure the throttle is opened. The mass flow from compressor two recovers and overshoots the other mass flow but does not push the other into surge, and after $0.5 \mathrm{~s}$ the flows are balanced. After slightly above $1 \mathrm{~s}$ the boost pressure has returned to the same level as before the disturbance. As a result of the drop in boost pressure the wastegates closes during co-surge until about $0.8 \mathrm{~s}$ when the boost pressure almost has recovered. This results in a torque drop after the initial transient between $0.3-1 \mathrm{~s}$ as the the wastegate closing increases back pressure and thereby pumping losses. A more advanced controller should also take this into consideration, but this serves to prove the concept of the control strategy.
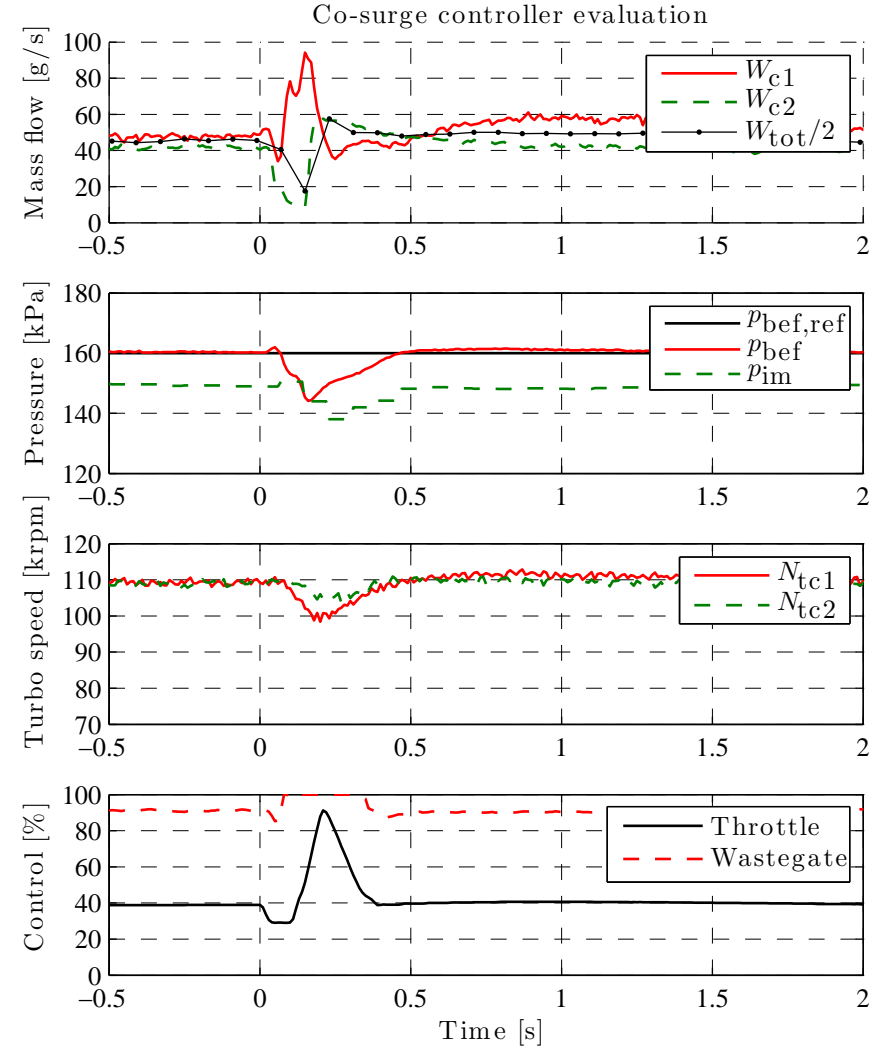

Figure 12: Evaluation of the controller (6)-(9) in the test vehicle. The overall behavior is similar to the measurement, the amplitude in mass flow and pressure drop, the surging mass flow overshooting the other at recovery, and the recovery time. The initial opening of the throttle differs due to the implementation, the disturbance is added to the throttle opening also after co-surge is detected until $0.3 \mathrm{~s}$.

The controller is also implemented in the test vehicle. The vehicle is mounted on a chassis dynamometer and driven with the engine in a similar operating point as the simulation. A throttle disturbance is introduced at $\mathrm{t}=0$, resulting in co-surge, see Fig. 12. After the disturbance the mass flows rapidly diverge, which is detected by the control system. The pressure drop over the throttle is larger than $\Delta p_{\text {lim }}$, and therefore only the throttle is opened. The mass flow rapidly recovers and the system has returned to the previous operating point in about $0.5 \mathrm{~s}$.

Comparing measurement and simulation the qualitative behavior is similar. The mass flow for the surging side drops rapidly, and when it recovers overshoots the other mass flow. The pressure drop in both simulation and measurement is about $10 \mathrm{kPa}$ and the turbo speeds diverge, although a little bit less in the measurement. The throttle closing is slightly faster in the measurement. This is a result of the boost pressure rising back to the reference faster than in the simulation, where there is a small undershoot in boost pressure.

\subsection{Turbo speed balancing during co-surge}

When the system enters co-surge the two turbo speeds start to diverge. The compressor which does not produce any flow accelerates while the other decelerates, and upon recovery the dif- 

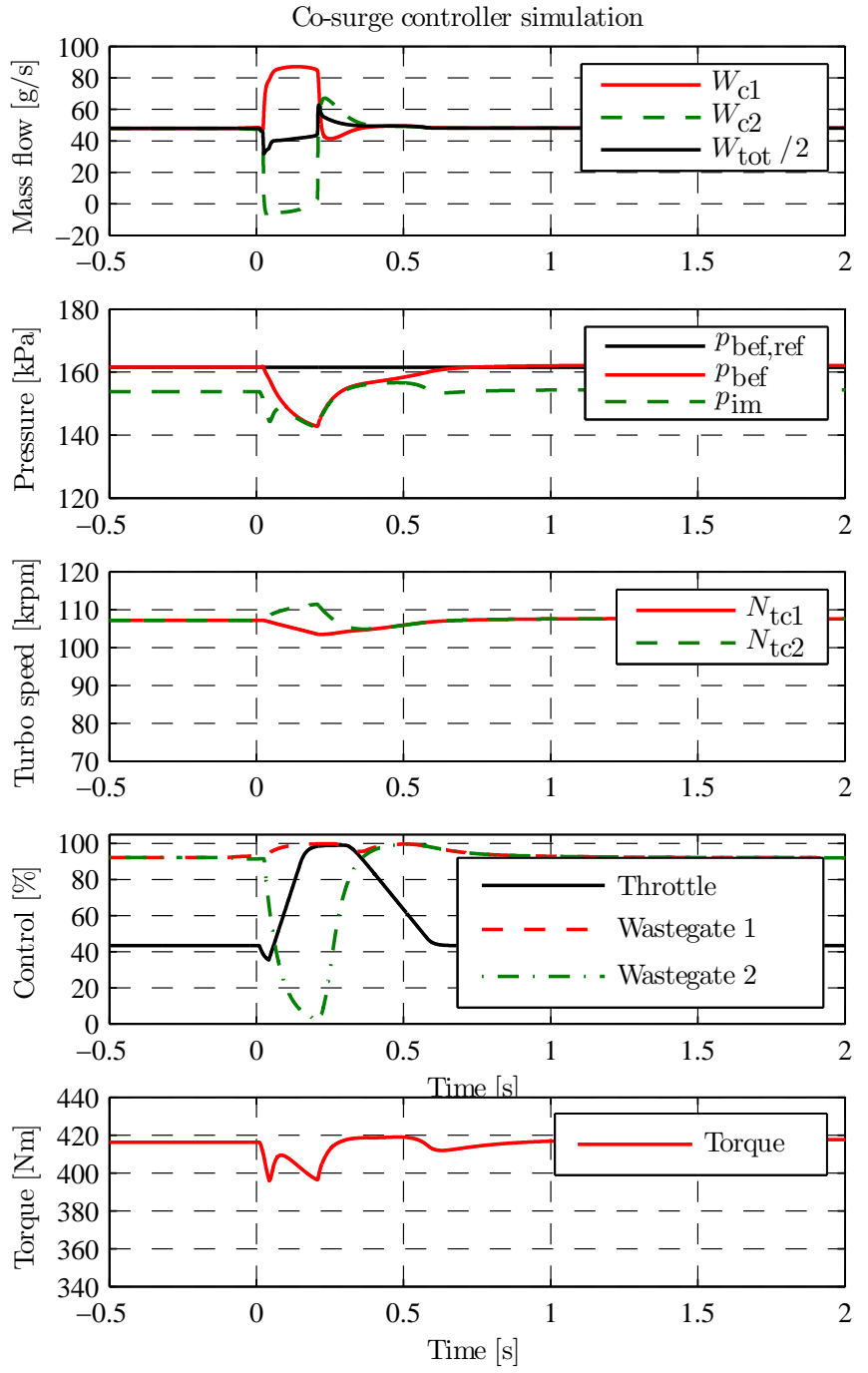

Figure 13: Simulation of the co-surge control strategy (6)-(9) together with the turbo speed balancing (10). Compared to the controller without balancing, the time with reversed flow is slightly longer, but the point of recovery is more balanced, with less mass flow overshoot for the recovering compressor.

ference in turbo speed will determine how unbalanced the operating point is and if the system will continue in co-surge. This was strengthened by the fixed speed simulation in Section 5, where only the compressor with lowest speed enters surge repeatedly. This suggests that if the system enters co-surge, the controller should try to control the compressor speeds as close together as possible. This makes the recovery point more balanced, hopefully avoiding that the other compressor is pushed into surge.

In this paper a PD-controller that tries to force the turbo speeds together during co-surge is proposed. An I-part would be too slow to contribute during surge, but could of course be used to keep the system balanced during normal operation. The controller acts on the wastegates, adding $u_{\mathrm{wg}}^{+}$to the control signal for the turbo with lower speed and deducting $u_{\mathrm{wg}}^{-}$from the
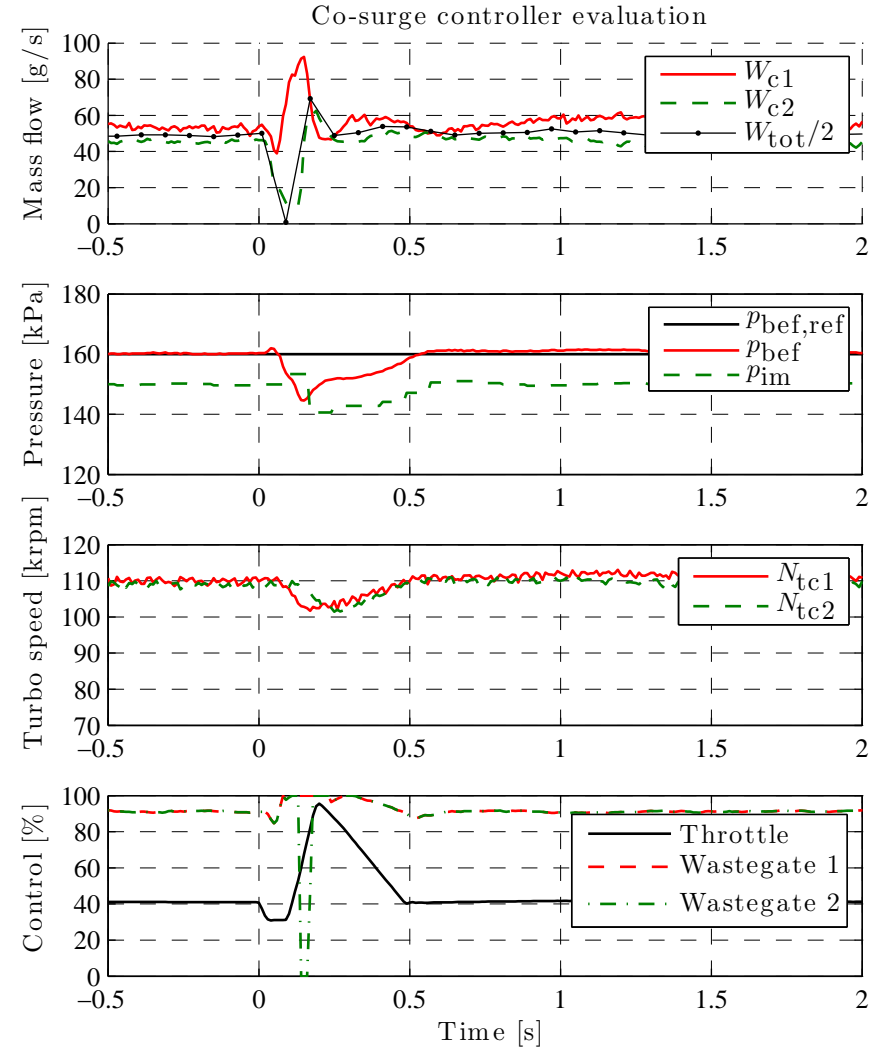

Figure 14: Evaluation in test vehicle of the co-surge control strategy (6)-(9) together with the turbo speed balancing (10). When comparing to the controller without turbo speed balancing the trend is the same as for the simulation. The recovery point is more balanced for both mass flow and turbo speed, and the boost pressure behavior is similar.

control signal for the turbo with higher speed.

$$
\begin{aligned}
& u_{\mathrm{wg}}^{+}=K_{\mathrm{wg}}^{+}\left(1+\tau_{\mathrm{wg}} s\right) e_{\mathrm{Ntc}} \\
& u_{\mathrm{wg}}^{-}=K_{\mathrm{wg}}^{-}\left(1+\tau_{\mathrm{wg}} s\right) e_{\mathrm{Ntc}}
\end{aligned}
$$

where $s$ denotes the Laplace variable and $\tau_{\mathrm{wg}}$ is chosen as the time constant for the wastegate actuator. The controller error, $e_{\mathrm{Ntc}}$, is the absolute difference in turbo speed, with a small dead zone, $N_{\mathrm{dz}}$.

$$
e_{\mathrm{Ntc}}=\max \left(\left|N_{\mathrm{tc} 1}-N_{\mathrm{tc} 2}\right|-N_{\mathrm{dz}}, 0\right)
$$

This balancing controller works in parallel with the control strategy for the throttle and bypass valves proposed in the previous section, described by (6)-(9). Since the turbo speed is differentiated in this controller it is necessary to filter the signals in order to reduce sensitivity to measurement errors. This is done with a third order Butterworth filter with a cut-off frequency of $20 \mathrm{~Hz}$ in the controller. Even in the filtered signals there will always be a small discrepancy between the turbo speeds, and to avoid unnecessary control action the dead-zone is used. This is mainly during recovery when the system is about to leave co-surge, but before the "end of co-surge" is detected.

The stabilizing effect of trying to balance the turbo speeds during co-surge is first demonstrated by the simulation 
in Fig. 13. Twin mass flow sensors used for detection. The engine is operated in the same operating point as before, with a disturbance introduced at $\mathrm{t}=0 \mathrm{~s}$. The system enters co-surge and the throttle opens. Additionally the wastegate of turbo one closes while the other opens, as a result of the diverging turbo speeds. Compared to the case without balancing in Fig. 11, the initial period with reverse flow is slightly longer. However, upon recovery the flows are converging faster, in approximately $0.4 \mathrm{~s}$ compared to $0.6 \mathrm{~s}$ for the controller without turbo speed balancing. The time until the system reaches the same operating point as before the disturbance is also smaller, about $0.7 \mathrm{~s}$ compared to $1 \mathrm{~s}$ without the balancing controller.

Corresponding results from the test vehicle is shown in Fig. 14. Compared to the controller without balancing, the overshoot of the recovering mass flow very short, $0.5 \mathrm{~s}$ after the disturbance the flows are equal, the recovering flow $W_{\mathrm{c} 2}$ drops slightly below $W_{\mathrm{c} 1}$ for another $0.2 \mathrm{~s}$.

The flows after recovery is almost equal, and on the same level as before the disturbance. The effect of the differentiated wastegate action on the turbo speeds is that the difference is reduced faster, resulting in the more balanced recovery point. The boost pressure response is very similar to both simulations and the previous controller. In conclusion the test vehicle experiments confirm simulation results, that forcing the turbo speeds together results reduces the overshoot of the recovering mass flow, reducing the risk of a continuing oscillation.

\section{Conclusions}

The paper presents data on co-surge and gives an analysis of the phenomena based on the movement in the compressor map. The analysis highlights the importance of the varying compressor speeds for the co-surge oscillation. During the surge cycle the turbo speeds diverge and if the difference at the recovery point is too high, the other compressor is pushed into surge and the oscillation continues. Co-surge detection with different sensors is investigated, and a general algorithm is proposed that can use any pair of the following sensors, either parallel pressure, mass flow or turbo speed. The fastest detection is with pressure sensors mounted close to the compressors, however, unlike mass flow or turbo speed sensors these are not suitable for balancing. A controller that aims to quell the co-surge oscillation and return to the previous operating point has also been presented and validated both in simulation and in a test vehicle. The controller is able to quell the oscillation and return to stable operation within less than $1 \mathrm{~s}$. Additionally turbo speed balancing is added to this controller, which reduces the imbalance in both mass flow and turbo speed at the point of recovery. This reduces the risk of a prolonged oscillation and has been evaluated both in simulation and test vehicle. The evaluations confirms that the mass flows are more balanced after recovery, shortening the time to regain balanced flow.

\section{Acknowledgments}

This research was supported by the VINNOVA Industry Excellence Center LINK-SIC.

\section{Appendix A. Nomenclature}

\begin{tabular}{|c|c|c|c|}
\hline Symbol & Description & Subscript & Description \\
\hline$A$ & Area & af & Air filter \\
\hline CS & Co-surge detected & $\mathrm{ac}$ & After compressor \\
\hline$c_{\mathrm{p}}$ & Specific heat & bef & Before throttle \\
\hline$D$ & Diameter & $\mathrm{bc}$ & Before compressor \\
\hline$\Delta \mathrm{X}$ & Difference in $X$ & bp & Bypass \\
\hline$e$ & Error & CS & Co-surge \\
\hline$\gamma$ & $c_{\mathrm{p}} / c_{\mathrm{v}}$ & $\mathrm{c}$ & Compressor \\
\hline$L$ & Flow plug length & fric & Friction \\
\hline$N$ & Rotation speed & $\mathrm{im}$ & Intake manifold \\
\hline$p$ & Pressure & $\lim$ & Limit \\
\hline$\Pi$ & Pressure ratio & ref & Reference \\
\hline$R$ & Gas constant & tc & Turbocharger \\
\hline SL & Speed line & thr & Throttle \\
\hline$T$ & Temperature & tot & Total \\
\hline $\mathrm{t}$ & Time & wg & Wastegate \\
\hline$t_{s}$ & Sample time & & \\
\hline$\tau$ & Time constant & & \\
\hline$u$ & Control signal & & \\
\hline$V$ & Volume & & \\
\hline$W$ & Mass flow & & \\
\hline
\end{tabular}

\section{References}

Ammann, M., Fekete, N. P., Amstutz, A., Guzzella, L., 2001. Control-Oriented Modeling of a Turbocharged Common-Rail Diesel Engine. In: Proc. of the Int. Conference on Control and Diagnostics in Automotive Applications.

de Jager, B., December 1995. Rotating stall and surge control: A survey. In: Proc. of the IEEE Conference on Decision and Control. Vol. 2. pp. 18571862.

Dixon, S., 1998. Fluid Mechanics and Thermodynamics of Turbomachinery, 4th Edition. Butterworth-Heinemann.

Emmenthal, K.-D., Hagermann, G., Hucho, W.-H., February 1979. Turbocharging small displacement spark ignited engines for improved fuel economy. In: SAE World Congr. Techn. Paper 790311.

Eriksson, L., 2007. Modeling and Control of Turbocharged SI and DI Engines. Oil \& Gas Science and Technology - Rev. IFP 62 (4), 523-538.

Eriksson, L., Nielsen, L., Brugård, J., Bergström, J., Pettersson, F., Andersson, P., October 2002. Modeling of a turbocharged SI engine. Annual Reviews in Control 26 (1), 129-137.

Galindo, J., Arnau, F., Tiseira, A., Lang, R., Lahjaily, H., Gimenes, T., April 2011. Measurement and Modeling of Compressor Surge on Engine Test Bench for Different Intake Line Configurations. In: SAE World Congr. Techn. Paper 2011-01-0370.

Galindo, J., Climent, H., Guardiola, C., Tiseira, A., 2009. On the effect of pulsating flow on surge margin of small centrifugal compressors for automotive engines. Experimental Thermal and Fluid Science 33 (8), 1163-1171.

Galindo, J., Serrano, J., Climent, H., Tiseira, A., 2008. Experiments and modelling of surge in small centrifugal compressor for automotive engines. Experimental Thermal and Fluid Science 32 (3), 818-826.

Gravdahl, J. T., 1998. Modeling and Control of Surge and Rotating Stall in Compressors. Ph.D. thesis, Norweigan University of Science and Technology.

Gravdahl, J. T., Egeland, O., September 1999. Centrifugal Compressor Surge and Speed Control. IEEE Trans. on Control Systems Technology 7 (5), 567579.

Greitzer, E., April 1976. Surge and rotating stall in axial flow compressorsPart I: Theoretical compression system model. J. of Engineering for Power 98 (2), 190-198.

Greitzer, E., June 1981. The Stability of Pumping Systems. J. of Fluids Engineering 103 (1), 193-242. 
Guzzella, L., Wenger, U., Martin, R., March 2000. IC-Engine Downsizing and Pressure-Wave Supercharging for Fuel Economy. SAE World Congr.

Hansen, K., Jørgensen, P., Larsen, P., 1981. Experimental and Theoretical Study of Surge in a Small Centrifugal Compressor. J. of Fluids Engineering 103 (3), 391-395.

Hendricks, E., Sorenson, S. C., 1990. Mean value modelling of spark ignition engines. SAE Trans. J. of Engines 99 (3), 1359-1373.

Leufvén, O., Eriksson, L., July 2008. Time to surge concept and surge control for acceleration performance. In: Proc. of the IFAC World Congr. Seoul, Korea, pp. 2063-2068.

Petitjean, D., Bernardini, L., Middlemass, C., Shahed, S. M., Hurley, R. G., March 2004. Advanced Gasoline Engine Turbocharging Technology for Fuel Economy Improvements. In: SAE World Congr. Techn. Paper 200401-0988.

Thomasson, A., Eriksson, L., 2011. Modeling and Control of Co-Surge in BiTurbo Engines. In: Proc. of the IFAC World Congr. Milano, Italy.

Thomasson, A., Eriksson, L., 2013. Co-Surge Detection and Control for BiTurbo Engines with Experimental Evaluation. In: Proc. of the IFAC Symposium on Advances in Automotive Control,. Tokyo, Japan.

Watson, N., Janota, M., 1982. Turbocharging the Internal Combustion Engine. The Macmillan Press ltd.

Westbrook, M., Turner, J., 1994. Automotive sensors. IOP Publishing.

Willems, F., de Jager, B., September 1998. Modeling and Control of Rotating Stall and Surge: An Overview. In: Int. Conference on Control Applications. pp. 331-335. 